\title{
Molecular Genotyping and Epidemiology of Mycobacterium tuberculosis Isolates Obtained from Inmates of Correctional Institutions of Campinas, Southeast Brazil
}

\author{
M.S. Moreira-Oliveira ${ }^{1}$, H.B. Oliveira ${ }^{2}$, F. Pace ${ }^{1}$, E.G. Stehling ${ }^{1}$, M.M.M. Rocha ${ }^{3}$, D.C.G. Aily ${ }^{3}$, M. Brocchi ${ }^{1}$, W.D. Silveira ${ }^{1}$ \\ ${ }^{1}$ Department of Microbiology and Immunology, $\mathrm{IB}^{1}$; ${ }^{2}$ Department of Preventive and Social Medicine of Medical Sciences School of State \\ University of Campinas; ${ }^{3}$ Division of Medical Biology from Adolfo Lutz Institute of Campinas; Campinas, SP, Brazil
}

\begin{abstract}
The objective of this study was to investigate the possible transmission of tuberculosis among 39 inmates with positive Mycobacterium tuberculosis smears in four correctional institutions located in Campinas City, SP, Brazil over a 19-month period. Fifty-one $M$. tuberculosis isolates from these inmates were characterized according to the number of IS6110 insertion elements present in their genomic DNA. The number of insertion elements in $M$. tuberculosis isolates varied from two to twelve. The dendrogram of similarity resulted in the grouping the isolates in six main clusters. These results, associated to epidemiological data, suggested the transmission of tuberculosis among inmates of the same and different institutions inmates. Univariate analysis of epidemiological data (total delay for beginning of treatment, previous treatment, and HIV status) and clustering occurrence showed that only "previous treatment" $(\mathrm{OR}=7.65, \mathrm{p}=\mathbf{0 . 0 3 2})$ was associated with the possible transmission of tuberculosis in the studied prisons.
\end{abstract}

Key-Words: Mycobacterium tuberculosis, transmission, molecular genotyping, Campinas, SP, Brazil.

Tuberculosis (TB) became a major public health problem during the Industrial Revolution, when city overcrowding and very poor living conditions created the ideal circumstances for the spread of diseases. Although several public health measures and effective drug treatments have reduced the incidence of TB, about one-third of the world's population is still infected [1], with eight million new cases and two million fatalities per year [2,3].

In the last decades, the trend of incidence of TB in developed and underdeveloped countries has risen due to the deterioration of public healthcare facilities, poverty, and migration. This resurgence, including multidrug-resistant Mycobacterium tuberculosis strains has also occurred among high-risk population such as the HIV-infected citizens [3]. Brazil is badly affected, with large urban centers like São Paulo City with TB incidence rates as high as 45.9/100,000 inhabitants [4].

Prison populations are considered at high risk of TB infection due to their socio-economic characteristics and prison living conditions [5]. A study of 1,052 inmates in nine São Paulo municipality prisons confirmed the high prevalence rate of inmates with active TB (2,065 per 100,000 inmates). This prevalence is around 70 as high as that found among the general Brazilian population [6]. Additionally, the prison population has increased dramatically in Brazil in the last years, making correctional institutions ideal places for person-toperson transmission of infectious diseases, including TB and

Received on 15 August 2008; revised 23 November 2008.

Address for correspondence: Dr. Wanderley Silveira. E-mail: wds@unicamp.br Fax: +55 19-3788.6268. State University of Campinas - Biology Institute - Microbiology and Immunology Department Rua Monteiro Lobato, Caixa Postal 6109, Zip code: 13081-862 Campinas - SP - Brazil. This work was supported by grants No. 97/ 05093-2 and No. 05/60928-0 from Fundação de Amparo à Pesquisa do Estado de São Paulo, and grant No. 303301/2002-3 from Conselho Nacional de Desenvolvimento Científico e Tecnológico.

The Brazilian Journal of Infectious Diseases 2008;12(6):487-493. (C) 2008 by The Brazilian Journal of Infectious Diseases and Contexto Publishing. All rights reserved. human immunodeficiency virus (HIV), either alone or associated [7]. Besides the inmates' highest risk of contamination by $M$. tuberculosis, prison staff and visitors are also at risk. The community living in contact with at-risk people and ex-prisoners are also considered as being part of the high-risk population. These data indicate that urgent measures are needed to not only detect and treat TB-harboring inmates, but also trace the transmission routes in the community and in prisons [8]. The control of TB depends mainly on its rapid and accurate diagnosis, its effective treatment, and thorough contact tracing [9].

Before the introduction of molecular biology techniques in the diagnosis of Mycobacterium infection, direct microscopy using Ziehl-Nielsen smear of early-morning sputum was the only rapid diagnosis method. However, a positive smear requires the presence of about $10^{4}$ acid-fast bacilii (AFB) per milliliter of sputum [9], which makes the diagnostic dubious at times.

To identify the TB route transmission, molecular biology tools such as polymerase chain reaction (PCR) [10], restriction fragment length polymorphism (RFLP) [11,12], and nucleic acid amplification (NAA) [13] have been used.

To the best of our knowledge, no molecular characterization of M. tuberculosis isolates from Brazilian male inmates has been carried out to date.

The objective of this study was to characterize TB isolates that were obtained from male inmates of different correctional institutions located in Campinas City, Southeast Brazil, and confirm TB transmission among same-cell and different institution inmates. We also studied the status of age, HIV infection, history of previous TB treatment, and treatment delays with disease transmission.

\section{Material and Methods}

Study Setting and Patient Population

This retrospective study was conducted at four different correctional institutions located in Campinas City, 
Southeast Brazil, from February 1997 to September 1998. Sputum examination of inmates with clinical signs of pulmonary TB and $M$. tuberculosis strain isolation and characterization were performed by Adolfo Lutz Institute, São Paulo, the national referral institute for infectious disease detection. Although a specific TB detection routine is not adopted in the correctional system in the Campinas region, all patients with clinical signs of TB confirmed by positive $M$. tuberculosis culture during the study period were included in this study. A total of 51 M. tuberculosis isolates from 39 inmates were evaluated. From some patients, more than one strain was isolated (Table 1). All strains had the insertion element IS6110 detected by polymerase chain reaction as described below.

This study was approved by the ethical committee of the Medical School of the State University of Campinas (UNICAMP).

Table 1. Strains isolated from the same inmate.

\begin{tabular}{cc}
\hline Patient/Strain & Date of strain isolation \\
\hline $14 / 19$ & 03.24 .97 \\
$14 / 20$ & 08.07 .97 \\
$14 / 21$ & 11.18 .97 \\
$14 / 22$ & 01.12 .98 \\
$14 / 23$ & 07.02 .98 \\
$20 / 30$ & 11.18 .97 \\
$20 / 31$ & 12.03 .97 \\
$18 / 27$ & 09.16 .97 \\
$18 / 28$ & 10.24 .97 \\
$12 / 16$ & 08.28 .97 \\
$12 / 17$ & 09.08 .97 \\
$29 / 40$ & 04.07 .98 \\
$29 / 41$ & 05.28 .98 \\
$11 / 13$ & 07.04 .97 \\
$11 / 14$ & 09.04 .97 \\
$11 / 15$ & 09.08 .97 \\
$8 / 8$ & 06.27 .97 \\
$8 / 9$ & 07.23 .97 \\
$8 / 10$ & 08.28 .97 \\
\hline
\end{tabular}

Epidemiological Characteristics

Epidemiological characteristics such as age, total treatment delay (time between symptom onset and the beginning of treatment), history of previous TB treatment, and HIV infection were obtained directly from the inmate TB Notification Index Cards and Criminal Records.

\section{Molecular Study}

In this study, the insertion element IS6110 of $M$. tuberculosis strains $[14,15]$ was used as a molecular marker for fingerprinting analysis throughout RFLP, as described below, and characterize the TB isolates that were obtained from inmates of different correctional institutions.
Bacterial DNA Extraction

Whole genomic DNA of M. tuberculosis was purified as previously described [16]. Briefly, M. tuberculosis colonies grown on Lowenstein-Jensen medium (LJ) were transferred to a micro centrifuge tube $(2 \mathrm{~mL}$ ) containing $1.5 \mathrm{~mL}$ of TE buffer (Sambrook et al. 1989) and heat-inactivated $\left(80^{\circ} \mathrm{C}, 1 \mathrm{~h}\right)$. After spinning (12,000 g, $5 \mathrm{~min}) 50 \mu \mathrm{L}$ of lisozyme $(10 \mathrm{mg} / \mathrm{mL})$ was added in and the tube was kept at $37^{\circ} \mathrm{C}$ for $6 \mathrm{~h}$. Next, $75 \mu \mathrm{L}$ of $10 \% \mathrm{SDS} / 10 \mathrm{mg} / \mathrm{mL}$ proteinase $\mathrm{K}$ was added in and the suspension was vortexed. The tube was heated at $65^{\circ} \mathrm{C}$ for 10 min and $100 \mu \mathrm{L}$ of $5 \mathrm{M} \mathrm{NaCl}$ was added in. After mixing, $100 \mu \mathrm{L}$ of CTAB $(1 \mathrm{~g} / 10 \mathrm{~mL}) / \mathrm{NaCl}(0.41 \mathrm{~g} / 10 \mathrm{~mL})$ was added to the tube under agitation and heated $\left(65^{\circ} \mathrm{C}, 10 \mathrm{~min}\right)$. DNA was extracted from the suspension using chlorophorm:isoamilic alcohol (24:1), precipitated with isopropyl alcohol, vacuum dried, suspended in $50 \mu \mathrm{L}$ of TE buffer and freeze stored.

\section{IS6110 Probe}

Primers IS1(5'-TGGGTCCGCCAGGCCCAGGTC-3') and IS3 (5'-GTAGGCGTCGGTGACAAAGGC-3') were synthesized using the IS6110 DNA sequence [14] and used to PCR amplify a 665pb DNA fragment located between bases 211 and 876 of this insertion element of a $M$. tuberculosis strain donated by Instituto Adolfo Lutz de São Paulo. The reactions were performed in a DNA thermal cycler (Perkin Elmer 480). The genomic DNA was denatured by heating at $94^{\circ} \mathrm{C}$ for $10 \mathrm{~min}$, followed by 25 cycles at $94^{\circ} \mathrm{C}, 1 \mathrm{~min} ; 63^{\circ} \mathrm{C}, 1 \mathrm{~min} ; 72^{\circ} \mathrm{C}, 2 \mathrm{~min}$. After DNA polymerization, the PCR product was purified using the Wizard DNA clean-up System (Promega), sequenced using the automated MegaBase sequencer (Amershan Biotech), and radioactively labeled $\left[\left(\alpha-{ }^{32} \mathrm{P}\right) \mathrm{dCTP}\right]$ using Oligolabelling Kit (Pharmacia LKB Biotechnology).

RFLP of M. tuberculosis Isolates Using the IS6110 Probe

Whole genomic $M$. tuberculosis DNA purified as previously described [16] was digested with restriction enzyme PstI (a enzyme that does not cut inside IS6110 element) and run in a $0.8 \%$ submersed agarose gel electrophoresis system. DNA transfer to nitrocellulose membranes and hybridization with the IS6110 probe under high stringency conditions were accomplished as described by Sambrook et al. [17].

\section{Statistical Analysis}

EPI-INFO 6.0 software [18] was used for statistical analysis of epidemiological data.Genomic diversity and similarity dendrograms were calculated by the UPGMA method [20] using the POPGENE software (Version 1.31) [19]. For the construction of the dendrogram, the presence of a given band (pattern) in a data matrix was coded as 1 and its absence, as 0.

\section{Results}

The 39 male inmates studied were aged between 21 and 63 , mean age of 34 (standard deviation of 10.8 years). Thirteen (33.3\%) patients did not have TB notification index card (Tables 2 and 3). 
Table 2. Criminal Record Sector epidemiological data of inmates.

\begin{tabular}{lrrr}
\hline Total treatment delay (weeks) & & & \\
\hline $0-4$ & 9 & 42.9 & 42.9 \\
$5-8$ & 5 & 23.8 & 66.7 \\
9 or more & 7 & 33.3 & 100 \\
Total & 21 & 100 & \\
Unknown & 18 & & \\
Previous treatment & & 77.1 & 100 \\
New case & 27 & 22.9 & \\
Retreatment & 8 & 100.0 & \\
Total & 35 & & 100 \\
Unknown & 4 & & \\
HIV status & & 48.3 & \\
Positive & 14 & 51.7 & \\
Negative & 15 & 100.0 & \\
Total & 29 & & \\
Unknown & 10 & & \\
\hline
\end{tabular}

Table 3. Coincident incarceration periods.

\begin{tabular}{cclc}
\hline Cluster patterns & Patients & Coincident periods in prision (month/year) & Patients \#: date of culture (month) (Prision) \\
\hline I & $22 ; 36$ & $06 / 97$ to 04/99 - PI & $22: 07 / 98(\mathrm{PI})$ \\
& & & $36: 03 / 98(\mathrm{PI})$ \\
V & $16 ; 28$ & 16 and 28: 01/97 to 12/97 - AN & $16: 09 / 97(\mathrm{AN})$ \\
& & & $28: 02 / 98(\mathrm{AN})$ \\
$\mathrm{X}$ & $19 ; 20$ & 19 and 20: 01/94 to 12/94 CD & $19: 11 / 97(\mathrm{CD})$ \\
& & and 06/92 to 01/93 - SB & $20: 02 / 97(\mathrm{AN})$ \\
XII & $24 ; 38$ & Without records for patient 38 & $24: 01 / 98(\mathrm{CD})$ \\
& & & $38: 07 / 97$ \\
XIII & $04 ; 17$ & coincident periods not found & $04: 04 / 97(\mathrm{AN})$ \\
& & & $17: 09 / 97(\mathrm{CD})$ \\
XVIII & $18 ; 25 ; 34$ & 18 and 25: 02/98 to 07/98 - AN & $18: 09 / 97(\mathrm{PI})$ \\
XX & $01 ; 07$ & da Rocha, diferent times before the exam & $01: 03 / 97(\mathrm{CD})$ \\
& & & $07: 04 / 97(\mathrm{PI})$ \\
XXVII & $08 ; 13$ & Without records for patient 13 & $08: 06 / 07 / 08 / 98(\mathrm{PI})$ \\
& & & $13: 09 / 97$ \\
\hline
\end{tabular}

Detention Houses: Anatolia Nogueira, CD: Casa de Detenção, CDSP: Casa de Detenção Flamínio Favero (São Paulo), PI - Penitenciária I, SB: Cadeia Pública do São Bernardo.

The analysis of the number of IS6110 insertion elements present in the genome of the $51 \mathrm{M}$. tuberculosis isolates demonstrated a copy number ranging from 2 to 12 with a mean number of 7 copies per isolate (Figure 1). These data allowed us the construction of a dendrogram of 30 IS6110 patterns (I-XXX) comprising 6 main clusters (A-F) (Figures 1 and 2) with most of the strains (43/84.3\%) in two clusters (A and B). Twelve patterns (40\%)(I, IV, V, X, XII, XIII, XV, XVIII, XIX, XX, XXII, XXVII) were considered identical clones with 2 (6.7\%), 5 (16.7\%), 2 (6.7\%), 3 (10\%), 2 (6.7\%), 2(6.7\%), 3(10\%), 4(13.3\%), 2 (6.7\%), 2(6.7\%), 2 (6.7\%), and 4 (13.3\%) strains, respectively (Figure 2). Strains 8-10 (pattern XXVII), 13-15 (pattern XV), 16-17 (pattern XXII), 19-23 (pattern IV), 27-28 (pattern XVIII), 30-31 (pattern X), and 40-41 (pattern XXIX) were isolated from the same inmates.
Analysis of inmate epidemiological data from the Criminal Record Sector (Table 3) indicated delays in starting treatment (time between symptom onset and the beginning of treatment) of $0-4$ weeks for 9 (42.9\%), 5-8 weeks for 5(23.8\%) and of 9 or more weeks for 7 (33.3\%) of the inmates. No data were available for 18 inmates. Twenty-seven (77.1\%) of the inmates were new TB cases, while 8 (22.9\%) had been previously treated. Data were not available on 4 cases. Additionally, 14 (48.3\%) had confirmed HIV infection, 15(51.7\%) were HIV negative and 10 had unknown HIV status. Among them, some inmates had lived in the same correctional institutes at least once during their historical period of incarceration (Table 3); however, there was no information if they had shared the same cell. Inmates 19(HIV?) and 20 (HIV) lived in two different 
Figure 1. Restriction fragment length polymorphism (RFLP) of DNA fragments containing IS6110 element/groups.

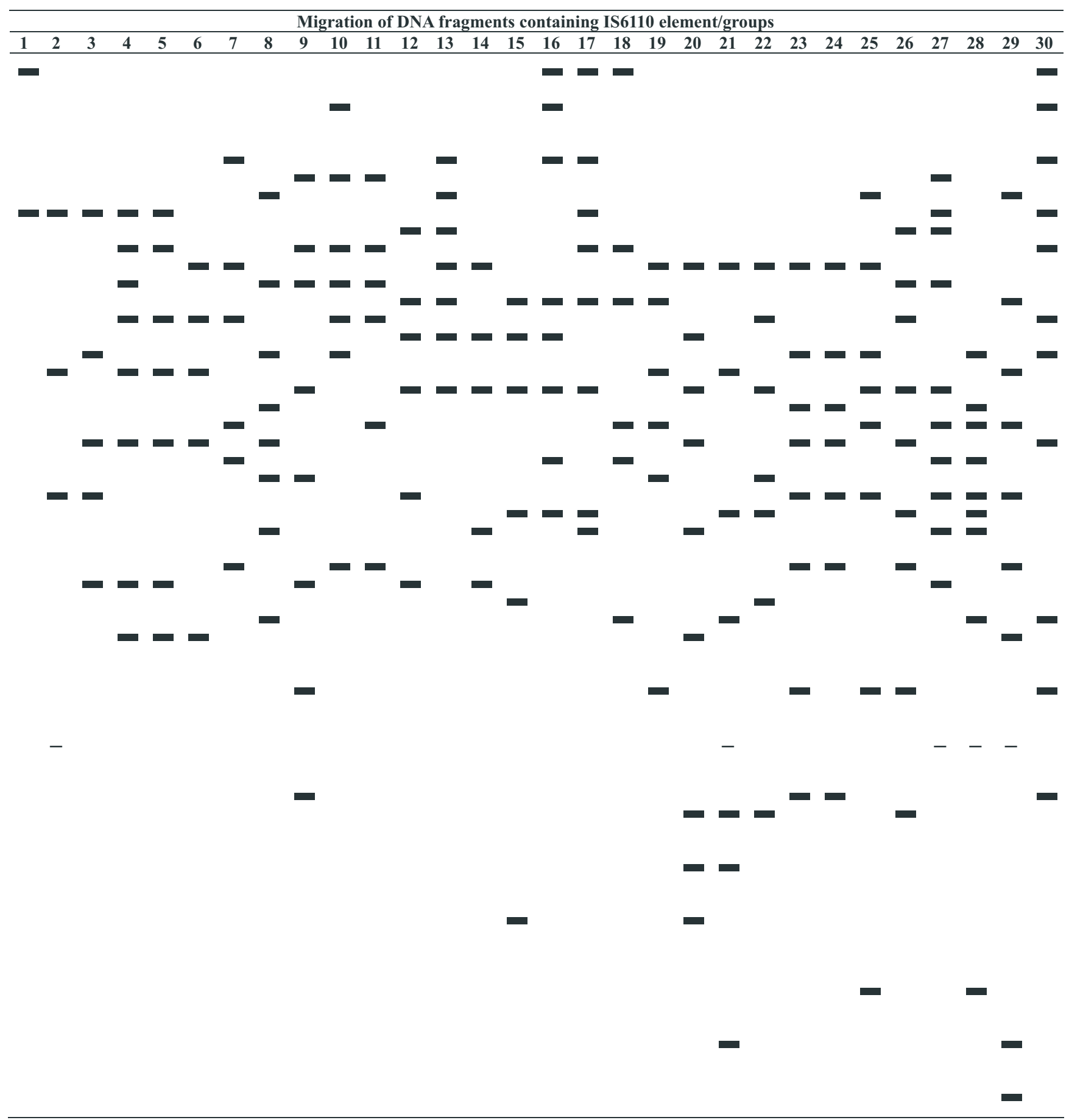

prisons during different periods of time (Table 2). The dendrogram of similarity (Figure 1 ) showed that inmates $22\left(\mathrm{HIV}^{+}\right)$and $36\left(\mathrm{HIV}^{+}\right), 16\left(\mathrm{HIV}^{+}\right)$and $28\left(\mathrm{HIV}^{-}\right), 19$ (HIV?) and 20 (HIV $\left.{ }^{-}\right), 24\left(\mathrm{HIV}^{\text {? }}\right)$ and $38\left(\mathrm{HIV}^{-}\right), 04\left(\mathrm{HIV}^{-}\right)$and 17 $\left(\mathrm{HIV}^{+}\right), 18\left(\mathrm{HIV}^{+}\right), 25\left(\mathrm{HIV}^{-}\right)$and $34\left(\mathrm{HIV}^{+}\right), 01\left(\mathrm{HIV}^{-}\right)$and 07 (HIV?), 08 (HIV) and 13 (HIV?) were colonized by $M$. tuberculosis isolates with identical RFLP profiles (same clones).

The univariate analysis of the epidemiological data and clustering occurrence showed that only variable "previous treatment” ( $\mathrm{OR}=7.65$, $\mathrm{p}=0.032)$ was associated with possible recent TB transmission within prisons (Table 4). 
Figure 2. Dendrogram of similarity (percent similarity) of Mycobacterium tuberculosis strains based on the RFLP of DNA fragments containing IS6110 element/groups.

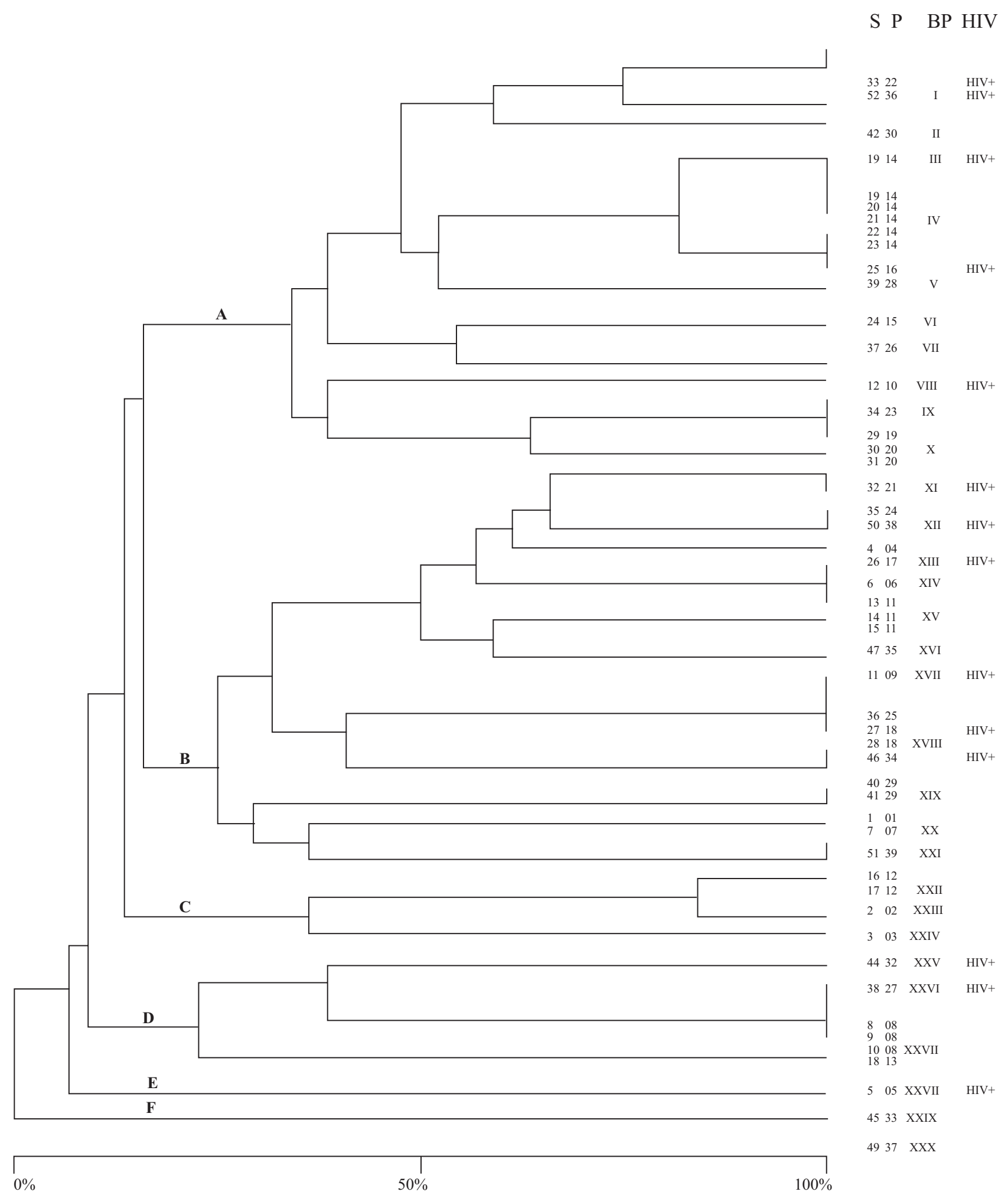

$\mathrm{S}=$ strains, $\mathrm{P}=$ patients, $\mathrm{BP}=\mathrm{RFLP}$ pattern, $\mathrm{HIV}^{+}$patients with history of HIV infection. 
Table 4. Univariate analysis of epidemiological data of the inmates and clustering occurrence.

\begin{tabular}{lcccc}
\hline Variables & Group I Cluster N(17) & Group II Non-Cluster N(22) & Odds ratio(OR) & Pvalue \\
\hline Age & 12 & 16 & 1.13 & 0.99 \\
$\geq 30$ & 4 & 6 & 1 & \\
$<30$ & 9 & 2 & 7.65 & $0.032^{*}$ \\
Previous treatment & 10 & 17 & 1 & \\
$\begin{array}{l}\text { Retreatment } \\
\text { New cases }\end{array}$ & 7 & 7 & 2.0 & 0.594 \\
HIV status & 5 & 10 & 1 & \\
Positive & & & & 0.669 \\
Negative & 7 & 5 & 1.75 & \\
Treatment delay (weeks) & 4 & 5 & 1 & \\
5 or more & & & & \\
$0-4$ & &
\end{tabular}

* Significant value.

\section{Discussion}

Molecular biology can provide the epidemiologist with powerful techniques to better discriminate between infectious agents with either extended generation time or difficult to characterize by the usual identification methods. $M$. tuberculosis is an infectious agent that presents both drawbacks. Among the molecular techniques used to characterize Mycobacterium strains, rRNA region polymorphism [21], the analysis of the number of IS6110 sequences $[11,15,22]$ present in mycobacterium genome by either RFLP [22] or PCR [7,10], and DRE-PCR [7,23] are useful and practical tolls to differentiate isolates.

In the last years, considerable efforts have been made to precise the epidemiology and characteristics of $M$. tuberculosis strains isolated in different regions of Brazil [7,24-31]. Some Brazilian authors [26,27,29,32] demonstrated the usefulness of the IS6110-restriction fragment length polymorphism for typing Brazilian M. tuberculosis strains, but Ferreira et al. [24] were the first to apply it to determine strain types in female inmate populations in São Paulo City, Brazil. Ferreira et al. [24] suggested that in 50\% inmates infection was a reactivation process of a previous latent infection, while in the $50 \%$, TB was transmitted within prison (exogenous infection). This indicates an epidemiologic picture with harsh consequences for inmates, their families, and the community.

In this study, we also used the characteristic insertion element IS6110 of M. tuberculosis [15,22] to typify the isolates obtained from different inmates incarcerated in different correctional institutions in Campinas area and to verify the transmission of TB between the same and different correctional institution inmates.

Our results agree with previous works $[7,27,32]$ utilizing the detection of insertion element IS6110 in Brazilian M. tuberculosis isolates, which demonstrated that the number of this element per genome may vary (2-12 copies per genome). Our results also demonstrate that most of the isolates may be allocated to two main clusters. This denotes that just a few strains may be responsible for the colonization of the hosts and prevail due to the close proximity between inmates, as corroborated by Ferreira et al. [24], who studied 350 female inmates and found only seven RFLP patterns for the studied M. tuberculosis strains.

Furthermore, 17/39 (43.5\%) individual with identical IS6110 profiles lived at least once close together during their incarceration history and 7 (41.1\%) of them were HIV positive (Table 3). These data altogether strongly suggest cross contamination of inmates living in the same and in different prisons. If this assertion is also true for HIV infection, the virus infecting the prisoners needs be further genotyped.

The results herein obtained also indicate an association among previous TB treatment, level of education, and recent transmission of TB. These results agree partially with those published by other Brazilian authors [7,27]. In our study, HIV infection was not associated with isolate clustering, although $48.3 \%$ of the patients were HIV positive. Under-notification or lacking inmate historical records may be a problem in epidemiological evaluations [33]. In this study, 33\% of the inmates did not have disease notification index cards, which provide compulsory disease information to public health agencies. The lack of historical records for these inmates and the absence of clinical, demographic, and epidemiological data (Table 2) impaired an accurate analysis of association between TB and other diseases.

A remarkable epidemiological aspect of TB is the origin and spreading of multidrug resistant strains (MDR). Patients with MDR strains do not respond to treatment with commonly used drugs [7,28,34-36] and their treatment is long and expensive. Among the MDR screening features is the interruption of treatment and indiscriminate use of chemotherapy $[7,28]$. In a country like Brazil, with steadily rising incidence of criminality and high prison population turnover, it becomes necessary to follow up these patients and their contacts. Since this situation may be even worse in cities with bigger or a larger number of penitentiaries, our results suggest that treatment delay and inmate cross 
contamination may contribute to the origin of strains with increased drug resistance. This urges for the adoption of public health measures by correctional officer to improve TB diagnosis and cure rates and avoid posing high risk to inmates, prison staff, and the general population.

\section{References}

1. World Health Organization, Report 2006. Global Tuberculosis Control. 2003. [Online]. http//:www.who.int/tb/global_report/ 2006/full_report.pdf

2. Njoku A.K. Tuberculosis: current trends in diagnosis and treatment. Niger J Clin Pract 2005;8:118-24.

3. Frieden T.R., Sterling T.R., Mansiff S.S., et al. Tuberculosis. Lancet 2003;362:887-99.

4. Centro de Vigilância Epidemiológica. Reports on chronic diseases: tuberculosis. [Online]. http://www.cve.saude.sp.gov.br. 2004.

5. Aerts A., Habouzit L., Malakmadze N. Pulmonary tuberculosis in the prisons of the ex-USSR state of Georgia: results of nationwide prevalence survey among sentenced inmates. Int J Tuberc Lung Dis 2000;4:1104-10.

6. Abrahão R.M., Nogueira P.A., Malucelli M.I. Tuberculosis in country jail prisoners in the western sector of the city of Sao Paul, Brazil. Int J Tuberc Lung Dis 2006;10:203-8.

7. Baptista I.M.F.D., Oelemann M.C., Opromolla D.V.A., Suffys P.N. Drug resistance and genotypes of strains of Mycobacterium tuberculosis isolated from human immunodeficiency virusinfected and non-infected tuberculosis patients in Bauru, São Paulo, Brazil. Mem Inst Oswaldo Cruz 2002;97:1147-52.

8. Cone J.E., Harrison R., Katz E., et al. Tuberculosis transmission to prison employees during an outbreak among prisoners at two California prisons. J Health Safety 2000;4:75-9.

9. Pfyffer G.E., Brown-Elliot B.A., Wallace R.J. Jr. Mycobacterium: General characteristics, isolation, and staining procedures. In: Murray P.R., Jorgensen J.H., Pfaller M.A., Yolken R.H. (eds) Manual of clinical microbiology, $8^{\text {th }}$ ed. Washington, District of Columbia, pp 2003:532-59.

10. Cheng V.C., Yam W.C., Hung I.F., et al. Clinical evaluation of the polymerase reaction for the rapid diagnosis of tuberculosis. J Clin Pathol 2004;57:281-5.

11. Van Soolingen D. Molecular epidemiology of tuberculosis and other mycobacterial infections: main methodologies and achivements. J Intern Med 2001;249:1-26.

12. Doroudchi M., Kremer K., Basiri E.A., et al. IS6110-RFLP and spoligotyping of Mycobacterium tuberculosis isolates in Iran. Scand J Infect Dis 2000;32:663-8.

13. Cheng V.C.C., Yew W.W., Yuen K.Y. Molecular diagnostics in tuberculosis. Eur J Clin Microbiol Infect Dis 2005;524:711-20.

14. Thierry D., Cave M.D., Eisenach K.D., et al. IS6110, an is-like element of Mycobacterium tuberculosis complex. Nucleic Acids Research 1990;18:188.

15. Spurgiesz R.S., Quitugua T.N., Smith K.L., et al. Molecular typing of Mycobacterium tuberculosis by using nine novel variablenumber tandem repeats across the Beijiing family and low-copynumber IS6110 isolates. J Clin Microbiol 2003;41:4224-30.

16. Ausubel F.M., Brent R., Kingston R.E., et al. Current Protocols in Molecular Biology. Greene publishing associates, Brooklyn, NY, 1988.

17. Sambrook J., Fritsch E.F., Maniatis T. Molecular cloning: a laboratorial manual - $2^{\mathrm{a}}$ ed. - Cold spring Harbor Laboratory Pres. EUA, 1989.

18. Dean A.G., Dean J.A., Burton A., Dicher R.C. Epi-info version 6.0: a word processing database and statistics program for epidemiology on microcomputers. USD Incorporated, Stone Montain, Georgia, 1997.

19. Yeh F.C., Boyle F.T., Rongcai Y., Ye Z., Xiyan J.M. Popgene 1.31 version: microsoft window-based freeware for population genetic analysis. [online] University of Alberta. http://www.ualberta.ca/ $\sim$ fyeh/fyeh, 1999
20. Nei M. Estimation of average heterozygosity and genetic distance from a small number of individuals. Genetics 1978;89:583-90.

21. Viana-Niero C., Gutierrez C., Sola C., et al. Genetic Diversity of Mycobacterium africanum clinical isolates based on I Lenght Polymorphism Analysis, Spoligotyping and Variable Number of Ta. J Clin Microbiol 2001;39:57-65.

22. Diraa O., Elmdaghri N., Laadoudi L., et al. IS6110 restriction fragment length poluymorphism of Mycobacterium tuberculosis isolates from an area of Casablanca, Marocco. Int J Tuberc Lung D 2005;9:1294-6.

23. Dela A., Sajduda A., Pawlowska I., Dziadek J. Molecular characterization of Mycobacterium tuberculosis isolates from Lodz, Poland: analysis by IS6110 restriction fragment length polymorphism and double-repetitive-element PCR. J Infect. 2006;52:346-53.

24. Ferreira M.C., Ferrazoli L., Palaci M., et al. Tuberculosis and HIV infection among female inmates in São Paulo, Brazil: a prospective cohort study. J Acq Immun Def Synd H Retrovir 1996;13:177-83.

25. Lima M.M., Belluomini M., Almeida M.M.B., Arantes G.R. Coinfecção HIV/tuberculose: necessidade de uma vigilância mais efetiva. Rev Saúde Pública 1997;31:217-20.

26. Ivens-de-Araujo M.E., Fandinho F.C., Werneck-Barreto A.M., et al. DNA fingerprinting of Mycobacterium tuberculosis from patients with and without AIDS in Rio de Janeiro. Braz J Med Biol Res 1998;31:369-72.

27. Fandinho F.C.O., Kritski A.L., Hofer C., et al. RFLP patterns and risk factors for recent tuberculosis transmission among hospitalized tuberculosis patients in Rio de Janeiro, Brazil. Trans Royal Soc Tropic Med and Hyg 2000;94:271-5.

28. Lourenço M.C.S., Grinztejn B., Fantinho-Montes F.C.O., et al. Genotypic patterns of multiple isolates of $M$. tuberculosis from tuberculoses HIV patients. Tropic Med Intern Health 2000;5:488-94.

29. Suffys P.N., Ivens de Araújo M.E., Rossetti M.L., et al. Sefulness of IS6110-restriction fragment lenght polymorphism typing of Brazilian strains of Mycobacterium tuberculosis and comparison with an international fingerprint database. Res Microbiol 2000;151:343-51.

30. Carvalho A.C.C., Nunes Z.B., Martins M., et al. Clinical presentation and survival of smear-positive pulmonary tuberculosis patients of a university general hospital in developing country. Mem Inst Oswaldo Cruz 2002;97:1230-55.

31. Rocha A.S., Barreto A.M.W., Campos C.E.D., et al. Novel allelic variants of mycobacteria isolated in Brazil as determined by PCR-restriction enzyme analysis of hsp65. J Clin Microbiol 2002;40:4191-6.

32. Calusni A.L.R., Roscani G.N., Villares M.C.B., et al. IS6110 restriction fragment lenth polymorphism of Mycobacterium tuberculosis isolated from patients with pulmonary tuberculosis in Campinas, Brazil. Evidence of intercontinental distribution of strains. Mem Inst Oswaldo Cruz 2003;98:655-8.

33. Oliveira H.B., Cardoso J.C. Tuberculose no sistema prisional de Campinas, São Paulo, Brasil. Pan Am J Public Health 2004;15:194-9.

34. Kremer L.S., Besra G.S. Current status and future development of ant tuberculosis chemotherapy. Expert Opin Investig Drugs 2002; 11:1033-49.

35. Loddenkemper R., Sagebiel D., Brendel A. Strategies against multi drug-resistant tuberculosis. Eur Respir J Suppl 2002;36:66s-77s.

36. Höfling C.C., Pavan E.M., Giampaglia M.S., et al. Prevalence of katG ser315 substitution among isoniazid-resistant Mycobacterium tuberculosis isolates from Southeartern Brazil. Int J Tuberc Lung Dis 2005;9:87-93. 